\title{
Predicting international students' academic success... may not always be enough: Assessing Turkey's Foreign Study Scholarship Program
}

\author{
JULIE MATHEWS \\ MA TEFL Program, Bilkent University, Ankara, Turkey
}

\begin{abstract}
In 1993, Turkey's Higher Education Council (YOK) launched a program to sponsor thousands of students for graduate study abroad, in the hopes of building up a base of highly qualified, foreign educated faculty for 24 newly established universities nationwide. With an incoming new YOK administration in 1995, dramatic changes were made in the program's selection procedures. One of the key elements of these changes was the inclusion of a high foreign language proficiency requirement, which served both to meet certain ideological goals of the new administration as well as presuming to reduce the high degree of student failure abroad. In addition to assessing the overall success of the scholarship program in light of the changes made, this study provides another look at the connection between language proficiency and academic success, with both qualitative and quantitative data collected from 23 'YOK scholars'. Although finding a positive relation between language proficiency and academic success, the study suggests that rather than having solved the scholarship program's problems by imposing high language proficiency requirements, the new YOK administration actually reduced even further the program's ability to successfully supply faculty to the new universities. Recommendations are made for the Turkish and similar foreign study programs.
\end{abstract}

Keywords: academic success, developing countries, English as a foreign language, foreign scholarship programs, higher education, language proficiency, postgraduate education, Turkey

\section{Introduction}

The criteria used by the Turkish Higher Education Council (YOK) in its selection of students to receive scholarships for graduate study abroad have undergone significant changes over the past 10 years. Prior to 1993, students were occasionally hand-picked by individual universities for international study, but it was not until that year that, concurrent with the opening up of 24 new universities across the country, a largescale scholarship program was initiated and a centralized written exam was offered to allow applicants from across Turkey to compete for scholarships in predetermined disciplines. The great difficulties faced in subsequent years by many of the selected students led to greatly 
increased expenditures for the Turkish government, as students were being required to take several semesters of English language courses before their North American universities would allow them to begin full-time content area studies. Even after this training, some students were unable to keep up with the work requirements and were forced to accept an M.A. in place of a Ph.D., or to leave the program without successfully completing any degree.

There were a variety of possible explanations for the struggles of some of these first participants in the program, ranging from organizational difficulties of the hastily planned selection process, to failure to adequately prepare the students before sending them abroad. Incoming YOK officials appointed in 1995 seemed however, to focus their attention on the demographic make-up of the scholarship students, many of whom came from outside the "inner circle" of Turkey's elite. This attitude was very much consistent with their overt overall mission to stem what they saw as rising Islamist control over educational institutions, and their subsequent positions on such issues as women's right to wear head-scarves in universities or for secondary children to attend religious Imam Hatip schools. ${ }^{1}$ YOK's worries over financial considerations along with its concerns about the success of rural and potentially pro-Islamist students in the open exam, led to a reevaluation of both the ideological and technical bases of the program. One of the critical technical changes that was subsequently made in the selection process was to impose a high English proficiency requirement of applicants. Such a requirement served their ideological purposes of shifting the scholarship student profile to a more comfortable, urban elite one, while at the same time appearing to solve the program's problem of student failure abroad.

In order to assess the program in light of the changes made by the YOK administration, it seems that two separate indicators of 'success' must be considered: (1) were the selected students successful in their academic studies abroad, and (2) was the program successful in meeting its primary objective of providing professors for the newly established universities? In this study I attempt to address both of these questions. In looking at the first, I explore the cases of 23 current or former participants in the scholarship program, both via a written survey and through a small quantitative assessment of three factors that could possibly be correlated with their academic success abroad: educational background, amount and type of English language training, and sponsoring institution. In discussing the second question, I draw on 
interviews conducted with past and present YOK officials as well as on Turkish media coverage of the issue.

Given the political implications of, in particular, the second of the above questions, it is important that I make clear from the outset my own starting position on certain issues, as well as my personal relationship with the YOK scholarship program. I am married to a 'successful' YOK scholar, selected in the 1993 process. My husband completed both his M.A. and Ph.D. in North America, and is now an associate professor in the Turkish university system. He is not an active participant in this study, though his attitudes and experiences have undoubtedly affected my interpretations. As a member of Turkey's rural population, a former government employee, and a life-long beneficiary of fully government-sponsored education, my husband is both sociologically and educationally a believer both in the secularist state and in its role as an equalizer and as a helper of the poor in society. I share with him a philosophical opposition to an exclusionary, elitist education system in Turkey, on the grounds that exclusion of presumed conservative, Anatolian, or Islamist sectors of society could in fact undermine the country's developmental project by cutting off communication, increasing divisiveness, and reducing the hope for greater mutual understanding.

\section{Predicting academic success}

The primary changes made in the selection process of the Turkish scholarship program were, to a greater or lesser degree, ideologically influenced. They also reflected, however, the genuine understanding among YOK officials that by requiring high level English scores and high GPAs of the applicants, they could reduce the rate of student failure abroad. In fact, the larger literature concerning the predictability of students' success in higher education has been at best unimpressive in its ability to reach a consensus. When we look at such studies focusing on native English speaking students, many seem to suffer from problems of design and interpretation, thus, the often contradictory results may be linked to such problems as (a) the constructs for judging and measuring success, (b) the validity of the measures used as predictors, (c) the vast number of contextual factors which make generalizations difficult if not impossible, and (d) the uncontrolled variables involved in predicting success, which call into question the results of some studies. 
Some studies have evaluated the predictive ability of various test scores vs. that of entering grade point average (EGPA). Bieker (1996) found EGPA and the Graduate Record Examination (GRE) to be slightly better predictors than the Miller Analogies Test (MAT) for students in M.Ed programs, while Wesche et al. (1989) found the Graduate Management Assessment Test (GMAT) to be more predictive of performance in graduate management studies than EGPA. Noble's (2002) analysis of predictor variables however, found the EGPA to be the strongest predictor of success. The difference between the results for EGPA could be explained by contextual factors and study-design, for example, Wesche's study was with a large group in one specific discipline, while Noble's was of a small group of students in a general introductory research course. A further difference was that in the former, success was determined by both GPA and program completion, while in the latter success was related solely to performance in one course.

Another study of success in graduate education studies (Perney 1994) showed no predictive ability for any one variable, but found that a combination of EGPA, MAT scores, and a holistically judged writing sample proved to have moderate success in predicting the students' GPA in graduate school. Also supporting a combination approach to predictability with studies in specific disciplines were McClure et al. (1986), in which the undergraduate institution and undergraduate major were added to EGPA to successfully predict success in an MBA program, and Case and Richardson (1990), in which variables of gender and ethnicity were added to EGPA and GRE scores to predict success. In a further recognition of the complexities involved in attempting to predict success - as measured by GPA - Sinkavich (1994) showed that the use of metamemory and student motivation were significantly correlated with performance.

These studies reveal some of the difficulties involved in predicting success for native-speaking students in one discipline or class. The results are equally if not more problematic when the students under investigation are performing in a language other than their native one. As Kim and Sedlacek (1995) point out, in the case of international students (as opposed to refugees or permanent residents), the very issue of defining success can prove significant. Success may be considered in some studies as purely academic, while others may take into consideration its more social aspects, such as the students' relations with professors and fellow students, or the cultural experience itself. 
Even when focusing only on academic success, there has been disagreement over the role that language ability plays. Many studies (for example, Hwang and Dizney 1970; Sharon 1972; Shay 1975; Stover 1982; Hale et al. 1984; Graham 1987; Light et al. 1987; Johnson 1988; Bers 1994; Stoynoff 1997; Seelen 2002) have concluded that there is no or only moderate correlation between language proficiency and academic success. Some of these studies can be faulted for their reliance on the Test of English as a Foreign Language (TOEFL) as the sole measurement of language ability. The complexity of the concept of language proficiency is well established and in particular the difficulty of measuring the variety of English language skills necessary for academic success has been pointed out (see in particular Cummins 1983). Even the creators of TOEFL recognize the inadequacy of their test to fully measure language ability for academic purposes and, accordingly, made major revisions as a part of the TOEFL 2000 project (Turner, 1998, personal communication).

Despite the results of these studies, it remains a logical assumption that adequate language proficiency is at least important for successful academic performance by international students, and indeed many studies have shown a positive correlation between the two. From an American perspective, Brecht and Walton's (1994) analysis of study abroad programs stated that the "important role of language competence" is in vital need of further examination. A few studies of international students studying in North America (Eid and JordanDamschot, 1989; and Wardlow 1989) have shown a significant and predictive correlation between language ability and academic success.

Clearly, studies with both native and non-native speakers of English, attempting to correlate one or more factors with academic success have often proven contradictory or inconclusive. However, the reasons behind this lack of clarity may have had more to do with methodology than with any inappropriateness of the research question. Moreover, it is obvious that studies which have looked at a combination of variables to predict success have resulted in higher degrees of predictability than those which concentrated on one variable, e.g. a single test. For the purpose of this study of international students therefore, I chose to focus on English language ability as the major predictive factor, taking into consideration as well the additional variables of the amount of previous academic study, the institution(s) of previous study, and the institution to which the student had been assigned to return to. Bearing in mind the methodological problems of some previous studies, I also redefined both the measures of success 
and of English proficiency, according to the specific context under investigation.

\section{Background of the Turkish Foreign Study Program and its Selection Procedures}

In 1992, under the direction of then president Mehmet Saglam, YOK set out a bold new initiative to promote the growth and stimulation of Turkey's underdeveloped regions. With the rather sudden granting of a huge financial backing, a massive project was quickly put together to provide top quality instructors for the 24 new state universities being opened in regions outside of the major cities of Ankara, Istanbul, and Izmir. Through this scholarship program, selected students would receive full scholarships to study abroad and in return would agree to work at a new state university for twice the number of years of their international study.

Mr. Saglam was himself a graduate of an international institution, holding a Ph.D. in Public Administration from Columbia University. By his own account, he had arrived in New York knowing only a handful of words in English, but through hard work and perseverance was able to successfully complete his graduate studies and return to a distinguished career in Turkey. In a talk given to a group of recently arrived YOK scholars at the George Washington University in early spring of 1994, Mr. Saglam spoke of his confidence that they, like him, would be able to overcome the difficulties they would inevitably face. In an interview I held with him several years later, he also spoke of his understanding of the program and of his subsequent decisions regarding the selection process. It was his desire to see a full representation of Turkish youth being sent abroad which led to the decision to create a centralized exam based solely on field or content knowledge. The very small foreign language section included on the exam was reportedly given little or no emphasis during the selection process because, in his words:

Only $2 \%$ of Turkish undergraduates have had the training to reach a level of English that would allow them immediate access into an American university. It was my duty to make this scholarship program open to the $98 \%$ who hadn't had that training. (Saglam interview, January 12, 2001.) 
Of the 6897 students who wrote the exam in 1993, a total of 1282 students were sent abroad, with the vast majority, 745 and 446 respectively, being sent to the United States and Great Britain.

The 1992 projections for 700 students to be sent abroad each year until 1998, with an additional 620 being sent in both 1999 and 2000, were suddenly and drastically cut back with the 1994 selection, which was made under the direction of incoming YOK president Kemal Guruz. Mr. Guruz, who remained in his position as president of the Council until February 2004, represented the more common face of the educated elite in Turkey, having come up through the ranks of the country's English-language institutions before going abroad to study, and holding as one of his primary missions his commitment to preserving the secularist principles of Ataturk. In a recent talk given in the United States, in which he reflected on his time and actions as the president of YOK, Mr. Guruz described what he saw as a clash of worldviews between one based on rational human thought, and one based on divine revelation, and his on-going fears that some in Turkey are intent on turning the country away from a longstanding drive towards the former. He explained that both as citizen and as YOK president, it has been his "duty to oppose...and resist and thwart" (Guruz, unpublished) such attempts. Consequently, in addition to reducing the total number of scholarships to 131 in 1994 (with 64 and 52 going to the US and UK), the YOK administration under Mr. Guruz also set out to completely revise the selection process for the scholarship program.

The first revision was an immediate change in the format of the written exam. Students were no longer tested on content knowledge, but were given a GRE-style test of math and analytical/logic skills. Younger age limits were set in place - 25 for M.A. applicants (formerly 26) and 27 for Ph.D. applicants (formerly 28) - and minimum GPA requirements were raised from 2.50 to 2.80 (or, on a scale of 10 from 6.5 to 7 , and on a scale of 100 from 65 to 70). Language requirements were set at a 550 TOEFL score for students applying for North American schools (6.0 on the British International English Language Testing System), and restrictions were set allowing for only one semester of English as a Second Language (ESL) or English for Academic Purposes (EAP) study abroad. Upon receiving the scholarship, students were given one year to find an acceptance at a foreign university. If they failed to do so in that time, they would lose their right to the scholarship.

A second major change was made before the 1996 selection process began. After writing and passing the GRE-style exam, students would 
now be required to find an unconditional acceptance at one of the selected number of foreign institutions, requiring actual GRE scores and in some cases TOEFL scores above 550. They would then submit a file to YOK including their acceptance papers, test scores, letters of recommendation, transcripts and thesis proposal. Finally, they would be interviewed personally by a YOK committee. According to one student who was selected in 1996, this interview was before a panel of six council members, and consisted of questions about the student's thesis proposal, her reasons for wanting to study abroad, and her ability to successfully complete studies in a foreign language.

According to a former YOK committee member, the purpose of the interviews was a means for stopping "unworthy" people from being sent abroad - an assessment he described as those people who managed to get the minimum score on the written exam but who "were not, on face to face interview, teacher material". He added that committee members were prohibited from asking direct questions about religious or political background as a means of determining suitability for sponsorship, but that the Council was concerned about those students who might be considered as "more likely to experience cultural difficulties abroad". In explaining both the rationale behind the interviews and the reasons behind the early participants' failures he explained:

These individuals [chosen in the earlier selection process] came from somewhat modest backgrounds. They were not, in almost no cases, from the Bogazicis, Bilkents or METUs (a reference to the top English medium universities in Turkey - author's note) of this country, and their mothers and fathers weren't able to help. It's quite a psychological shock to be picked up from Konya or Yozgat, and they come to Ankara or Istanbul and, as it is, it's like... "ah", a culture shock, and then throw them into New York, or Columbus or Washington DC, and they close up. That's why they fell with only Turks or a kind of Islamic radicals who were not Turks necessarily. And this is something, again, in the interview process, they try to assess how much determination and maturity these people have (Interview with YOK official, Dec. 14, 2000).

According to subsequent figures, 175 students submitted competed files to YOK in 1996, of which 61 were asked to take the oral exam. Sixty students entered the oral exam, and 28 were accepted to receive full scholarships. Of these, five rejected the scholarship, resulting in a total of 23 students being sent abroad to study. ${ }^{2}$ 
While the changes made in the selection process in the mid-1990s clearly reflect ideological shifts in the YOK administration, it is also evident that the foreign language requirements were a particularly crucial element in the changes. The language proficiency requirements both served to exclude certain elements of Turkish society and also seemed a legitimate argument for ensuring the success of the students abroad. The questions remain however: were the students chosen under the new selection process indeed more successful abroad, and did the new selection process serve to meet the program's overall goals in a more successful manner?

\section{Method}

In looking at the factors that seem to be related with the students' success abroad, and taking lessons from the methodological shortcomings of some previous studies, I first sought to determine a definition of student success that would correspond with YOK's pragmatic needs of meeting time constraints and the need for students to complete their programs. Specifically, three categories were defined:

(3) Success, meaning that the student either successfully completed a Ph.D, or successfully completed an M.A. and is currently finishing up a $\mathrm{Ph}$.D. without any apparent problems concerning time limits.

(2) Moderate success, meaning that either this student was able to finish an M.A. but was able to do so only in 4 years and was unable to subsequently get an acceptance into a Ph.D. program, or that the student is currently enrolled in a Ph.D. program but has reached the end of the scholarship time limit without having completed comprehensive exams or having submitted a thesis proposal.

(1) Failure, meaning the student dropped out of school without completing any degree successfully.

In terms of the factors I wanted to consider as having possible correlations with success, I again designed scales that I felt could better reflect the particular contexts of these students. Thus, I first created a measure of English language ability according to the following point scale:

1pt. Turkish HS/BA/(MA). No English except for regular high school classes of 2-3 hours per week. 
2pts. Turkish HS/BA/(MA), regular high school English, plus one year of intensive English preparatory classes OR an extended (6-10 months) non-academic stay in an English-speaking country.

3pts. English-medium HS, Turkish BA/(MA).

4pts. Turkish HS, English-medium BA/(MA) at either Bosphorous University (BU) or Middle East Technical University (METU).

5pts. Turkish HS, English-medium BA/(MA) at Bilkent University. 6pts. English-medium HS, English BA/(MA) at either BU or METU. 7pts. English-medium HS, English BA/(MA) at Bilkent.

Such a scale is better able than a single test score to reflect these students' English proficiency, since it takes into consideration the nature of the previous language use, for example academic language use, intensive language study, and non-academic English use.

I also assigned students points according to the university in Turkey where the student had studied prior to winning the scholarship, and the amount of study they had had. Since some students were in the middle of graduate degrees when they were sent abroad, they were given $1 / 2$ the points for that particular degree. I defined the points as:

$1-$ BA at a 3rd tier school $2-$ MA at a 3rd tier school $3-$ Ph.D. at 3rd tier school

2 - BA at a 2nd tier school 3 - MA at a 2nd tier school 4 - Ph.D. at 2nd tier school

$3-\mathrm{BA}$ at BU/METU $4-\mathrm{MA}$ at BU/METU $5-\mathrm{Ph} . \mathrm{D}$. at BU/METU

$4-$ BA at Bilkent $\quad 5-$ MA at Bilkent $6-$ Ph.D. at Bilkent

This criterion and the points determined have less to do with the presumed content knowledge obtained (though that too no doubt plays a role in success), and more with the degree to which the students' previous studies could be considered as helpful in preparing the student for study abroad, primarily for the U.S. higher education system. Thus I took note of the language of instruction as well as the style of instruction at their former schools. The points were also determined in light of the Turkish state university system, which can be considered as having three tiers. The top schools consist of the English-language instruction schools, Bosphorous University (BU) and Middle East Technical University (METU), the second tier schools consisting of the 
established Turkish language universities or partially English-medium universities located in the major cities of Istanbul, Ankara and Izmir, and the third tier schools consisting of the remaining universities either those located outside the major urban centers or those new private universities in the urban centers. ${ }^{3}$ Turkish students are admitted to state universities on the basis of a centralized exam in which students with the highest scores enter what are considered the top schools. This rating system reflects the state's assessment of how the schools rank.

Bilkent is a competitive, private, English-medium university located in Ankara. On my rating chart it is considered as slightly higher than BU or METU based, as noted above, not on an assessment of the quality of the instruction, but rather on what I, as someone who has taught at both Bilkent and METU, perceive as the former's stricter adherence both to English language use in class and on assignments (the staff includes many native-English speakers), and to a "North American" style of classroom management and course requirements (e.g. class participation, more written assignments, greater emphasis on critical thinking, etc.).

As a third and final possible factor related to student success, I also considered the students' sponsoring university. These schools were rated simply as:

\section{3 - BU/METU}

2 - schools located in or near Istanbul or Ankara

1 - all others

This factor was of particular interest for the students sent abroad prior to 1996 because of the nature of the selection and assignment process at that time. Prior to 1996, students were allowed to choose their first, second, and even third choice of the new state universities for which they would agree to work. Naturally, in any given field there were one or two options that were located in or near large cities, and others located in less developed regions of the country. The students who received the top scores on the tests were then assigned to their first-choice school; students performing quite well went to their second choice, and so on. One problem with this system was that most students I spoke with formally or informally, checked off the best-located, urban schools for their first and second choices since these schools were considered the "best" of the new universities. This meant that the schools in the rural areas were assigned students who either (A) were not top performers and were therefore being sent to their last choice school, or (B) were students actually from those regions who wanted to remain there. Since 
each school had a certain number of positions to fill, it is theoretically possible that for a particular department, essentially anyone who listed an "unpopular" school as a choice would be selected, regardless of their actual performance on the written test. If, for example, 500 students chose Gebze Technical (located on the outskirts of Istanbul) for electrical engineering while only 15 checked off Urfa University (located near the Syrian border), and both schools had 10 possible openings, then a student from the first group had only a 1 in 50 chance of getting a scholarship, and therefore had to perform extremely well in order to get chosen. Since this was a norm-based test however, the student who chose Urfa had only to outperform five other applicants.

\section{Data collection}

In compiling the student case studies, I sent out an email request to current and former YOK scholars via an active listserve they have set up for themselves. Twenty-three wrote back agreeing to complete an openended survey by email. Admittedly a small number for quantitative tests, I felt this potential problem was offset by the complementary indepth qualitative data gathered from the open-ended surveys. More importantly however, I needed to determine that the experiences and opinions of these individuals could, in a sense, speak for those of the many hundreds of their fellow YOK scholars. In most ways, I think they do. These participants generally reflect the total number of students sponsored, in terms of the particular years they were sent and in terms of academic disciplines. The vast majority (17) was from the 1993 selection process, four were from 1994/95, and two were from 1996. In terms of their disciplines, eight were in engineering (mechanical, computer, electrical and petroleum), five were in political science/international relations, two were in physics, two were in management and accounting, and one each in educational psychology, biology, hospitality and tourism management, law, history, and fine arts. Turning to the participants' places of origin and their sponsoring universities, there was a wide range among those from 1993 and 1994, similar to that of the larger group of YOK scholars from those years. The participants from the later years were from Ankara and Istanbul, again reflecting the general profile of those years.

As for whether their overall experiences are representative, particularly when we consider the high percentage of my participants who ultimately did not return to work in the Turkish university system, I 
believe that findings from other studies as well as certain newspaper reports, suggest that they are. Of the 23 participants in this study, six (all from 1993/94) were fired by YOK, some on overtly ideological-based charges, others not. ${ }^{4}$ This number roughly reflects what I was told by a YOK official, who said that about "one-third" of those sent in 1993 were found to be "inappropriate" (Interview, Dec. 14, 2000). Of the four participants who were unable to complete any degree abroad, all had chosen at the time of the study to remain in the United States. The high total number among my participants of non-returnees and of those fired by YOK can be seen to be reflected in the real-life shortage of faculty that is now shaking the Turkish higher education system. Recent studies and reports on brain drain (Cumhuriyet 2000, 2001; Tansel and Gungor 2002) show that brain drain is a growing problem in Turkey, and government reports tell of a shortage of 19,000 academicians in 2000 , projected to reach 35,000 by 2005 (SPO 2000).

\section{Predicting Student Success Abroad}

I used the Statistical Package for the Social Sciences (SPSS) to look for statistical correlations between the students' success in their studies abroad and their English knowledge, academic background, and sponsoring university. I also used the students' self-reports in the email survey. Both quantitatively and qualitatively, a significant relationship was found between the factors, with students of more advanced English levels, those with more education or education at higher quality Turkish universities, and those sponsored by the more prestigious new universities, achieving success. Students, who either failed abroad or only achieved moderate success, were found to have come in general from lower quality Turkish universities and to have had less experience in English.

In terms of the descriptive data, Table 1 shows the means of the 23 participants, divided into three groups according to the year in which they were chosen for a scholarship. These means show that the first group sent in 1993 was quite diverse. In fact their education scores range from one to seven, and their English scores from one to six. Similarly, their success rate shows a large standard deviation of 0.861 , reflecting the fact that of the 17 participants in this group there were 10 ranked as successful, three as moderately successful, and four as failed. The second group, those students selected in 1994/1995, has higher means in all categories than the students of the previous year and a greater 
Table 1. Means according to year sent abroad

\begin{tabular}{llllll}
\hline Year & & Success & English & Education & Sponsor \\
\hline \multirow{2}{*}{1993} & Mean & 2.352 & 2.647 & 2.882 & 1.470 \\
& $N$ & 17 & 17 & 17 & 17 \\
$1994 / 1995$ & SD & 0.861 & 1.497 & 1.866 & 0.514 \\
& Mean & 3.00 & 5.500 & 4.500 & 2.500 \\
& $N$ & 4 & 4 & 4 & 4 \\
1996 & SD & 0.00 & 2.380 & 1.00 & 0.5774 \\
& Mean & 3.00 & 7.00 & 8.00 & 3.00 \\
& $N$ & 2 & 2 & 2 & 2 \\
& SD & 0.00 & 0.00 & 0.00 & 0.00 \\
\hline
\end{tabular}

consistency between members. All were considered successful. The 1996 group shows the highest means of all, with an average English score of seven, an average education score of eight, and both participants ranking as successful.

\section{Success and English}

As Table 2 suggests, the results of the students in this study support the idea that higher English proficiency relates positively to student success. Of the four students who received the lowest success score of 1 (failure), all four had as well the lowest score of 1 in English, meaning that all their academic work had been done in Turkish and that they had no English study outside of the normal 2-3 hours per week with Turkish teachers in high school. Of the three students who received a success rating of 2 (moderate success), one again came from the lowest English category, one received an English score of 2 (meaning that all academic work was done in Turkish but the student had either one year of English

Table 2. English and success

\begin{tabular}{lcccccccc}
\hline English score & 1 & 2 & 3 & 4 & 5 & 6 & 7 & Total \\
\hline Successful & & 4 & 1 & 5 & & 2 & 4 & 16 \\
Moderately successful & 1 & 1 & 1 & & & & & 3 \\
Failure & 4 & & & & & & & 4 \\
Total & 5 & 5 & 2 & 5 & & 2 & 4 & 23 \\
\hline
\end{tabular}


preparatory class or had an extended stay for non-academic purposes in an English speaking country), and one had an English score of 3, meaning that the participant had gone to an English-medium high school but the higher education was done in Turkish. Of the 16 students who received the highest success score of 3, eleven came from an English category of 4 or above, meaning that they had completed at least 4 years of academic study in English following one year of intensive English preparatory study. One successful student also came from level 3 English, and the four remaining were from level 2 English. No students with a low level 1 English score achieved a success rating of 1 . The mean English score of those achieving success was approximately 4.6, the mean English score of those achieving moderate success was just under 2, and the mean of English level for those who failed was 1. On a Pearson test, the correlation between success and English was 0.649, which was significant at $p>0.01$ on a 2-tailed test.

The responses of the study participants also reflect this outcome, and as well offer some suggestions for why some studies may have concluded that English did not play a significant role in success. While every respondent made some mention of the importance of English to successful study results, the remarks differed in their emphases, with some stressing the need for oral skills and others focusing on writing/reading skills. More importantly, some students stressed the need to differentiate between academic and "normal" English:

“...even people with a certain level of English but without the experience of using it in an academic way have problems." Resp. 23

"I took an English course in TOMER but it was just non-functional for the type of English I needed for studying." Resp. 5

"I think definitely a good background of written and academic English is important." Resp. 7

"Coming to study at the undergraduate level in North America is significantly different than coming for graduate studies. At the undergraduate level, one is allowed to be at a transitory stage because this is a psychological experience shared by North Americans and non-North Americans alike. To the extent that all these people are transferring... to a university or a college denominates a common experience. Therefore, the language problem becomes a part of a transition problem. On the other hand, when one comes for graduate studies, it is easier to distinguish them as those coming for academic concerns. This might automatically mean the competence in the jargon of a certain field..." Resp. 21 
The need to distinguish academic English skills and the suggestion that this may be significant only at the graduate level may explain why studies looking at undergraduate students may not find a strong correlation between English and success. Because there are many more aspects of learning (e.g. socialization, maturation) which are a common part of the undergraduate experience and which transcend language issues, language itself may not be a strong predictor of success.

The question of the TOEFL's validity for assessing academic English ability was also addressed by several respondents. While one respondent did feel in general that "...there is a correlation between the TOEFL score and your English competence" (Resp. 18), many others were more critical:

"...TOEFL is not a good indicator of English. I know people who has very good scores in TOEFL but cannot speak English or cannot understand their classes." Resp. 8

"I also disbelieve TOEFL after my experiences..." Resp. 5

"I had many friend in university who studied English very extensively in their country and get between 590 to 625 on TOEFL several times but they could not speak and write in English." Resp. 15 "I think sometimes these scores (TOEFL) may be misleading for some reasons such as a lack of motivation. It seems to me some Turkish guys including myself have never gave a damn for these exams while...other students I met here are killing themselves to get a higher score than one another." Resp. 2

\section{Success and academic preparation}

The second factor I chose to look at in this study was the role of previous academic preparation - both in terms of years (type and number of degrees earned) and quality of the institution at which the student studied. As Table 3 shows, there is again a correlation between the factors. Of the four students who received the lowest success rating of 1 (failure), all four had as well the lowest level of education (a B.A. only from a 3rd tier university). Of the three students who were moderate successes, two again had the lowest score of education, and one had a level 2 education (a B.A. from a 2 nd tier university). Of the 16 students who were successful, five had a score of 3 (B.A. and M.A. from Turkish institutions or some combination of scores), five had a score of 4 (B.A.s from either BU or METU), one scored 5, two scored 6 (one had 
Table 3. Academic preparation and success

\begin{tabular}{llllllllll}
\hline Education & 1 & 2 & 3 & 4 & 5 & 6 & 7 & 8 & Total \\
\hline Successful & & & 5 & 5 & 1 & 2 & 1 & 2 & 16 \\
Moderate Success & 2 & 1 & & & & & & & 3 \\
Failure & 4 & & & & & & & & 4 \\
Total & 6 & 1 & 5 & 5 & 1 & 2 & 1 & 2 & 23 \\
\hline
\end{tabular}

2 B.A.s, one year of law school, and had started an M.A., all at 2nd tier universities, the other had a B.A. from Bilkent and had started an M.A.), one scored 7 (with a B.A., and M.A. and the first year of a Ph.D. from a 2nd tier school) and two scored 8 (both with B.A.s from METU and M.A.s from Bilkent). The average education level of those achieving success was approximately 4.6 , the score of those achieving moderate success was about 1.3 , and of those who failed the average education score was 1 . On a Pearson test this correlation between education and success was found to be 0.714 which was significant at $p>0.01$ on a 2-tailed test.

Again, the responses and comments of the participants seem to clearly indicate a connection. Many of the students who had studied at BU, METU or Bilkent displayed both a confidence in the quality of their previous education and a belief that they were well prepared because the requirements and workload were quite similar:

"coming from an English language university I was accustomed to the system." Resp. 19

"For METU/BU/Bilkent the system of education there is not much different." Resp. 22

"In terms of reading I do not see any difference between here and METU." Resp. 23

"We didn't have much different." Resp. 18

"There was not much difference in our studies." Resp. 2

"METU provides high quality education which makes the adaptation process easier." Resp. 3

On the other hand, most respondents who had attended 3rd or 2nd tier universities voiced very different opinions:

"In Turkey we did not have to study that hard. You begin to study one week before the exam week." Resp. 5

"One of my biggest problems was my background was not strong enough from my undergrad." Resp. 1 
"Everything was more in America - reading, writing, class participation, better professors." Resp. 20

"I did not have that much workload in Turkey, even in my M.A. A good background is very helpful and can make everything easier." Resp. 11

\section{Interplay between English and education}

What is of course difficult to assess from a separate analysis of English/ success and education/success is whether or not one variable is more important and able therefore to compensate for a low score on the other. The problem for measuring this is that the two variables are inextricably tied since the two top-tier universities and Bilkent are all English-medium institutions. However, an individual analysis of a few cases that seem to go against the expected outcomes may shed some light on the complex interplay between success and both English and education.

Four students had low-level English scores of 2 and therefore might have been predicted to achieve only moderate success but were in fact successful in their studies. All four students had only studied English seriously for 1 year, either in a preparatory class or abroad in nonacademic circumstances. However, respondent 10 had extensive academic experience in his particular discipline, having earned both a B.A. and an M.A. and having begun his Ph.D. in that field, and respondent 11 had both a B.A. and an M.A. in her field. Respondent 12 also had extensive though more diverse academic experience, having earned two B.A.s simultaneously, and having finished (again simultaneously) 1 year of law school and 1 year of an M.A. at the time of being sent abroad. The fourth student, respondent 20, also had a B.A. and the first year of an M.A. at 2nd tier schools, but had in addition managed to get sponsorship from a local business organization in his hometown to go abroad to London, where he supported himself by working for 10 months.

In each of these cases there are factors to be considered which are not all easily measured. For example, high motivation or ambitiousness may have played a role in the success of respondents 12 and 20. The fact that the former was able to successfully complete two B.A. degrees in 4 years and was also able to successfully finish the first year of law school while simultaneously taking M.A. courses and holding down full-time 
employment clearly indicates a strong ability to handle intensive and difficult academic pressures. Respondent 20's similar abilities are attested to by the fact that despite having been cut off from the YOK scholarship after completing his M.A. (he was suspected as having Islamist sympathies), he had little difficulty obtaining a full scholarship and a full-time Teaching Assistant position in a Ph.D. program at a highly rated American university.

The success of respondent 11 may reflect in part the department in which she was a student. Her particular department was not a very highly ranked one in her field, being vastly overshadowed by wellknown, large biology departments at other universities in the same city. It should also be noted that this respondent took the maximum number of years to complete her Ph.D. The cases of respondents 10 and 11, both of whom had completed higher degrees in their field in Turkey, also may lend support to those studies on the importance of content knowledge in literary acquisition, which have shown that students with advanced content schemata could conceivably fare better (at least in some disciplines) than others with higher English language skills but less content capabilities (see for example Shih 1992).

\section{Success and sponsoring university}

The final variable I considered was success and the sponsoring university. As Table 4 shows, 14 of the 16 successful students were sponsored either by BU/METU or by a new university located in or near Ankara or Istanbul. Of the nine students sponsored by new schools outside of these areas, only two were successful. It is important to remember that for the 1993 group, everyone was assigned sponsorship to a new university, (i.e. not BU or METU), so with only two exceptions, all the successful participants were being sponsored by the relatively

Table 4. Success and sponsoring university

\begin{tabular}{llllc}
\hline Sponsor & BU/METU & Near Ankara or Istanbul & Others & Total \\
\hline Successful & 4 & 10 & 2 & 16 \\
Moderate Success & & & 3 & 3 \\
Failure & 4 & 10 & 4 & 4 \\
Total & 4 & 9 & 23 \\
\hline
\end{tabular}


prestigious new universities, and all moderate successes or failures were sponsored by the lesser quality/prestigious rural schools.

\section{Discussion}

The above statistical calculations reveal significant correlations between students' English ability, their previous academic experience, and their sponsoring university, and these students' success during their studies abroad. Moreover, the comments given in the email surveys support these findings. In terms of what these results mean for an evaluation of the YOK program, there is no doubt that the adjustments made in the selection procedures had clear implications for the program's ultimate success or failure. By setting high academic and English cut-off points, and requiring an unconditional acceptance from a high-level North American university before being eligible to even apply for the oral exam, YOK definitely reduced the possibility of an "unsuccessful" student being sent abroad. However, while this exclusionary policy may in fact have solved the question of student failure abroad and therefore seem to spell success for the overall YOK program, it may in fact not so much have addressed the program's problems as disguised them. It is important to not lose sight of the first priority of the program, which was to provide well-trained faculty for regional universities and, more indirectly, to thereby promote development for those regions.

It is clear that the later "face" of the YOK scholar and of the program itself became one that was no longer that of an open and unbiased means through which students from every corner of the country and from every socio-economic background were selected to go abroad, gain knowledge, and return to their country to share what they learned with their fellow citizens. Instead, we saw an average YOK scholar being one who probably attended English language schools from at least secondary school onwards, and who almost certainly has a degree from a top English-language university.

While the possible unfairness of the current selection process may not impress some of its supporters who are, rightly or wrongly, very much concerned with the need to protect secularist principles, it is also possible to present concrete arguments for why the later elitist policy can ultimately be considered as a failure - if we bear in mind the program's primary objective as outlined in 1993. With the later selection procedures, the regional universities are having a very difficult time filling their positions. The "new" type of YOK scholars are unlikely to be 
willing to fulfill contracts requiring them to serve for 8 or more years in a state university located far from Ankara or Istanbul. Some may choose to reject the scholarship - this may have been the case with the five out of 28 accepted scholarship recipients who rejected YOK's offer in 1996. Others may accept the scholarship, but then attempt to use family connections and influence to have themselves transferred from regional universities to one of the few urban ones. Though the possibility of this is vehemently denied by at least one YOK committee member, this does already appear to be the case for one of my respondents, who despite his only moderate success abroad, has been transferred to a top school in Istanbul. Most common, perhaps, is the possibility that those who accept the scholarship choose simply not to return to Turkey. Although YOK does not release official numbers, $16^{5}$ of the 23 students in my study have ultimately remained in North America or have returned to teach in private universities in Turkey. The issue of "brain drain," which is highly significant in many countries and has been studied for a long time (see for example Adams 1968; Oh 1977; Pruitt 1978; Barber 1985; Hertling 1997; Carrington and Detragiache 1999; Kurtulus 1999) needs therefore to be considered here from both the perspective of those students who choose to stay abroad as well as from the perspective of the students who do return to Turkey but who, ultimately, do not serve their term in the regional universities.

The fact is that state universities offer little in terms of financial reward (assistant professor salaries are approximately US\$700 per month). This may be compensated for in the top state schools, like METU or BU, with social and academic satisfaction - respect in the local academic environment, access to libraries and computers, and a relatively freer work schedule in a pleasant urban atmosphere. It would be unlikely that the products of YOK's new elite system would be willing to work without these perks, in regions far from the developed centers. Rather, it is clear that only students who come from those rural or less developed regions, students who feel that they are unlikely to get a better position, or students who feel they owe a great debt to the state, are likely to return willingly to these universities. As one comparative study of study abroad programs in Thailand and Zaire (Coleman 1984) concluded, the failure of the Zaire example was due to the selection of participants from only the elite sections of society. This seems to possibly hold true in the Turkish case as well.

On the other hand, it is impossible to ignore problems in the program that stem from the early selection process and administration as well. As pointed out by then-YOK president Mehmet Saglam, the Council's first 
priority in 1993 was to immediately set up and put into action this scholarship program so that by the year 2000 the country would start seeing returns on its investment in the form of large waves of returning faculty members. Time was of the essence; as he told me: "They only gave us about two months to plan everything. It was clear that if we didn't get the program up and running in that time, the money was going right back into the treasury, and we would lose our chance" (interview, January 12, 2001). Concerns about time constraints may have led to some planning and organizational errors being made. For example, inadequate advertising probably led to some disciplines having very limited pools of applicants to choose from. Since there was no defined cut-off score for acceptance, rather, the top scoring applicants in a given discipline - depending on how many were required - were selected, it is possible that in some cases students with poor academic records were sent abroad. In its early years the program also did not provide students with sufficient advice on how to proceed once they received the scholarship. There is definitely some legitimacy to the complaint by subsequent YOK administrators that some early participants may even have fallen victim to unscrupulous placement agencies and ended up at foreign institutions of dubious quality.

Furthermore, despite the admirable intent behind accepting students with virtually no English background, adequate measures were clearly not taken to prepare these students for academic study abroad. Some of the subsequent criticism for this aspect of the selection process was perhaps justified, as most of these students did indeed require a full year - and often more - of very expensive language preparation abroad. Although some language training was provided prior to going abroad, Mr. Saglam's personal experiences - including his own recollection of learning adequate English in 7 months to begin his graduate studies at Columbia - may arguably have distorted at least his expectations for other students. In fact, many students suffered a great deal in the first years. Some of the participants of this study admitted to breaking the rules and continuing to take extra English courses, others entered into content courses in which they were unable to understand the lectures and assignments. A well-organized, intensive year-long English preparation program carried out in Turkey could have alleviated some of their struggles, contributed to their overall academic success abroad, and also responded to the government's concerns about financial expenditures.

The overall picture that emerges when one looks at the Turkish foreign study scholarship program is one of mistakes being responded 
to with further mistakes. Early mistakes stemming from a variety of organizational problems were later interpreted primarily through a political filter and were therefore responded to in arguably an overly reactionary manner when the political opposition gained control of the High Education Council. Let's consider two of the main accusations of the later YOK administration: first, that a large number of Islamist and politically radical students were sent abroad in the first years of the program, and second that some of the new universities - those located in conservative regions of the country - were chosen by particularly conservative students as their "first choice" schools in the selection process.

It is true that the former YOK administration clearly says it hoped to make the program accessible to Turkey's non-elite majority, and among these, quite naturally, there were bound to be students who did not meet the subsequent administration's ideal profile. However, one YOK administration official's assessment that about " $1 / 3$ of the [early] students became more radicalized and fell in with radical Islamist groups," strikes me as an exaggeration. Furthermore, appealing primarily to such a cultural explanation stemming from a presumed political conspiracy to explain these students' academic problems seems inappropriate. Organizational problems of advertising, counseling, and planning can more likely explain the academic problems experienced by many early students.

As for the question of whether some of the new universities were in fact "political hotbeds" of Islamic conservatism, again there is no doubt that many new universities located in conservative areas probably attracted both students and aspiring faculty from more conservative backgrounds. Even the older, established Turkish universities in rural regions tend to reflect the area in which they are located, and thus tend to be more conservative than their urban counterparts. Attempting, however, to infuse the new rural institutions with liberal elitist faculty members in an attempt to convert the nature of these schools and their students may not have the desired effect. Both past and current YOK officials have stressed that it is their desire to have faculty members who have experienced foreign styles of teaching and higher education, foreign ways of thinking and analysis, and who can introduce these "Western ways" into the Turkish system. It can be argued that the earlier administration's attempt to do this via 'messengers' who were themselves representing the full range of Turkish society, was a better method. Students from the rural conservative regions may be more willing to listen to alternative and "Western" ideas if they come from faculty members who more closely resemble themselves and their own 
backgrounds, rather than from those who came up through Turkey's elitist education system.

\section{Recommendations}

Based on the results of this study and on this discussion two main recommendations could be made for the Turkish scholarship program as well for other developing countries' similar programs. The first involves the selection procedures and the second involves setting up an English for Academic Purposes (EAP) course for selected students.

\section{The selection procedures}

The best option for such programs seems to be a centralized written exam, which would be open to all students who have successfully completed an undergraduate university degree. Perhaps the best compromise for such as exam would be a combination of the 1993 and 1994/ 95 Turkish exams, in that it should include the testing of both contentbased knowledge and GRE-style math/analytical/logic skills. The problem with using solely the GRE-style test as a means of choosing students, who will be sent abroad to study in a foreign language, is that it fails to consider the significance of content knowledge.

By once again addressing content knowledge on the central exam, it would be also possible to reduce the necessity of relying on the GPA cut-off limits to determine eligibility. Limits such as these are problematic in many cases in that they presume a universally accepted agreement on what the scores mean. Such agreement is possible in the case of standardized tests, but is not necessarily possible in the case of GPA scores, which may differ greatly from professor to professor, and from university to university. In the Turkish case for example, there are three accepted ways of counting GPA (on a scale of 4, 10, or 100), making it even less likely that there will be consensus on the significance of those scores. As one of my respondents commented, the grading system in Turkey is "worse than ever" while that in the US is "very fair". A second respondent, also belonging to the successful category of the 1993 group, pointed out that he graduated third in his class at a respected Turkish-language university with only a 69 GPA, while the second and first students had approximate GPAs of 70 and 75 respectively. This would mean that under the 1996 revisions to the Turkish 
selection process, only the top student from that department would be allowed to apply for the exam. It is interesting to note that the respondent in this case successfully completed his Ph.D. studies abroad, and is now a well-published assistant professor in Turkey.

By broadening the scope of knowledge being tested, it would be also possible to minimize the chance that exists in Turkey of private 'courses' (dershaneler) popping up overnight to teach students all the skills necessary to pass the test. Such courses remove the probability of equalaccess since they are sufficiently expensive to be considered exclusionary towards students from poorer backgrounds.

Any criticisms of the fact that a more complicated exam such as this is expensive to administer, judge, and revise annually (in particular when compared to the current procedure), seem quite easily countered if we accept the basic argument that the social costs of continuing the current procedure will ultimately be much greater.

Despite its imperfections, there appear few options in the Turkish case for addressing the main question of how to supply teachers to the regional universities without returning to the original procedure of having students make their choices, and then be selected and assigned based on a norm-referenced test - though this time with some minimum criterion score required as well. If we look again at the 17 students in the 1993 sample group, it is quite possible to envision one single change in the YOK program which, given this same student body, would have probably resulted in most of the students being placed in the successful category as I have defined it. This is the introduction of a yearlong English for Academic Purposes (EAP) preparation class which would be offered in Ankara and Istanbul to all accepted YOK scholars who are unable to immediately get an unconditional acceptance from a highlevel North American institution. Following the successful completion of this proposed EAP course students would then be required to obtain an unconditional acceptance from an appropriate university within a certain time period. Failing to pass the course or to get the necessary acceptance would cause the student to lose his or her right to the scholarship.

\section{Conclusion and directions for further research}

This study has shown that while English knowledge and academic preparation are positive indicators of success in foreign study, YOK's politically inspired revision of the selection procedures which seem to 
respond to these findings in fact do not mean that the study abroad program itself will be more successful, since the program now risks failing to meet its minimum requirement of supplying professors to most of the new universities. A modified return to the previous selection procedures and the implementation of an EAP course could serve to address these issues.

Future studies need to be conducted which look further at the return issue as it pertains specifically to the Turkish context. One interesting perspective would be to look at the profile of students who do return how do they fit in to their assigned universities, how is their performance/productivity upon return, how do they view their role in the program for development, how much did they know about YOK's mission, and what role, if any, did this play in their decision to return. A second angle for research might be to consider the question of what would make YOK scholars more likely to return to their posts? How aware are current YOK scholars of the advantages of being in new universities, such as faster promotion? Results from studies such as these could further inform policy changes and lead to the greater success of the YOK - or similar - programs.

\section{Notes}

1. Under the YOK leadership beginning in 1995, strict bans were rigorously enforced to prevent women wearing headscarves from entering classrooms, and the entire structure of elementary education was altered. In the latter case, compulsory state education was extended from 5 to 8 years, thereby eliminating the growing numbers of private religious elementary schools. The YOK president of that time, speaking at a conference in Cornell University in late 2004, stated clearly that he saw it as his "obligation" to remain "vigilant" against Islamists who were seeking to "advance their cause by controlling educational institutions." Former YOK president Kemal Guruz, speaking at the conference on "European Turkey: Modernization, Secularism and Islam", December 3-4, 2004, Cornell University.

2. This study includes the statistics until 1996, as the students chosen between 1993 and 1996 tend to be finished with or nearing the end of their studies abroad. This year also marked the end of any significant push to find applicants for the new universities in particular. Since 1996, the numbers of students sent abroad annually has remained very small. The selection procedure has in essence returned to its pre-1993 form, with students applying or being recommended through their home institutions - primarily the strong, English medium universities in Ankara and Istanbul.

3. Two new private universities in Istanbul, Koc and Sabanci, are not included in this classification. Although new, both are quite respected schools. They are not in- 
cluded in this study however, since they were not yet open when the changes were being made.

4. Those fired on non-overt ideological grounds reported to me that the real reasons were nonetheless ideological suspicions. One participant who was fired on the basis of a technicality concerning his passport, told me that upon later meeting the man who had actually fired him, the man said, "what did you expect? We didn't even have a photograph of you, how were we to know you were such a modern type?" Communicated by email to me by participant 12 .

5. This number includes six participants who were fired and whose cases remain in court. All of the participants who failed in their studies have chosen to remain abroad. Of the seven who have returned, only one was assigned to a university outside of Ankara and Istanbul. Interestingly, all seven were selected to go abroad in either 1993 or 1994.

\section{References}

Adams, W. (1968). The Brain Drain. New York: MacMillan.

Barber, E.G. (1985). Foreign Student Flows: Their Significance for American Higher Education. New York: Institute of International Education.

Bers, T. (1994). English proficiency, course patterns, and academic achievement of Limited-English-Proficient community college students, Research in Higher Education 35(2), 209-234.

Bieker, R.F. (1996). Factors affecting academic achievement in graduate management education, Journal of Education for Business 72(1), 42-46.

Brecht, R.D. and Walton, R. (1994). Policy issues in foreign language and study abroad, AAPSS 532, 213-225.

Canale, M. (1983). From communicative competence to communicative language pedagogy, in Richards, J. and Schmidt, R. (eds.), Language and Communication. New York: Longman, pp. 2-27.

Carrington, W.J. and Detragiache, E. (1999). International migration and the brain drain, The Journal of Social, Political, and Economic Studies 24(2), 163-171.

Case, D.O. and Richardson, J.V. (1990). Predictors of student performance with emphasis on gender and ethnic determinants, Journal of Education for Library and Information Science 30(3), 163-182.

Coleman, J.S. (1984). Professional training and institution building in the third world: Two Rockefeller Foundation experiences, Comparative Education Review 28(2), 180-202.

Cumhuriyet Gazetesi (2001). 'Yuksek Sefalet' [Higher Poverty], July 16.

Cumhuriyet Gazetesi (2000). 'Beyin gucu: Arastirma gorevlisi azaliyor' [Brain drain: Research assistants are shrinking in number], January 14.

Cummins, J. (1983). Language proficiency and academic achievement, in Oller, J. (eds.), Issues in Language Testing Research. Rowley, MA: Newbury House, pp. 108-129.

Eid, M.T. and Jordan-Damschot, T. (1991). 'Needs assessment of international students at Eastern Oregon State College,' ERIC Accession number EDRS (326098.

Graham, J.G. (1987). English language proficiency and the prediction of academic success, TESOL Quarterly 21(3), 505-522. 
Hale, G., Stansfield, C., Duran, R. (1984). Summaries of TOEFL Studies, 1963-1982. Research Report No. 116, Princeton, NJ.

Hertling, J. (1997). More Chinese students abroad are deciding not to return home, Chronicle of Higher Education 43(29), 151-153.

Hwang, K. and Dizney, H.F. (1970). Predictive validity of the TOEFL for Chinese graduate students at an American university, Educational and Psychological Measurement $30,475-477$.

Johnson, P. (1988). English language proficiency and academic performance of undergraduate international students, TESOL Quarterly 22(1), 164-168.

Kim, S.H. and Sedlacek, W.E. (1995). International students: Distinguishing Non-Cognitive Variables from Social Interaction Patterns, Research Report (8-95, Maryland University College Park Counseling Center.

Kurtulus, B. (1999). Amerika birlesik develtleri'ne Turk beyin gucu [Turkish brain drain to the United States of America]. Alfa Basim Yayim Dagitim, Istanbul.

Light, R.L., Xu, M. and Mossop, J. (1987). English proficiency and academic performance of international students, TESOL Quarterly 21, 251-261.

McClure, R.H., et al., (1986). A model of MBA student performance, Research in Higher Education 25(2), 182-193.

Noble, R.F. (1987). 'Multiple regression analysis of predictor variables of academic achievement in the course introduction to research,' ERIC Accession number EDRS (274678.

Oh, T.K. (1977). The Asian Brain Drain: A Factual and Causal Analysis. San Francisco: R\&E Research Associates.

Perney, J. (1997). 'Using writing samples to predict success in a graduate college of education,' ERIC Accession number EDRS, (374701.

Pruitt, F.J. (1978). The adaption of African students to American society, International Journal of Intercultural Relations 2, 90-118.

Seelen, L.P. (2002). Is performance in English as a second language a relevant criterion for admission to an English medium university?, Higher Education 44, 213-232.

Sharon, A.T (1972). English proficiency; verbal aptitude, and foreign student success in American graduate school, Educational and Psychological Measurement 32, 425-431.

Shay, H.R., (1975). Effect of foreign students' language proficiency on academic performance. Dissertations Abstracts International 42.

Shih, M. (1992). Beyond comprehension exercises in the ESL academic reading class, TESOL Quarterly 26(2), 289-298.

Sinkavich, F.J. (1994). Metamemory, attributional styles, and study strategies: Predicting classroom performance in graduate studies, Journal of Instructional Psychology 21(2), 172-182.

SPO (2000). Sekizinci bes yillik kalkinma plani, 2001-2005 [Eighth five-year development plan, 2001-2005], State Planning Organization, Ankara.

Stover, A.D. (1982). Effects of language admission criteria on academic performance of non-native English speaking students. Dissertations Abstracts International 42.

Stoynoff, S. (1997). Factors associated with international students' academic achievement, Journal of Instructional Psychology 24(1), 56-68.

Tansel, A. and N.D. Gungor (2002). 'Brain drain from Turkey: Survey evidence of student non-return'. Unpublished paper, available on-line at www.erf.org.eg/uploadpath/pdf/0307.pdf. 
Wardlow, G. (1989). International students of agriculture in U.S. institutions: Precursors to academic success, Journal of Agricultural Education 30(1), 17-22.

Wesche, L.E., et al. (1989). 'A study of the MAT and GRE as predictors of success in M.Ed. programs,' ERIC Accession number EDRS (3100150. 